\title{
Primary and secondary prevention of stroke and systemic embolism with rivaroxaban in patients with non-valvular atrial fibrillation
}

\author{
Sub-analysis of the EXPAND Study
}

\author{
Shinichiro Uchiyama ${ }^{1} \cdot$ Hirotsugu Atarashi ${ }^{2} \cdot$ Hiroshi Inoue $^{3} \cdot$ Takanari Kitazono $^{4} \cdot$ Takeshi Yamashita $^{5}$. \\ Wataru Shimizu $^{6} \cdot$ Takanori Ikeda $^{7} \cdot$ Masahiro Kamouchi $^{8} \cdot$ Koichi Kaikita $^{9} \cdot$ Koji Fukuda $^{10} \cdot$ Hideki Origasa $^{11}$. \\ Hiroaki Shimokawa ${ }^{12}$ (D)
}

Received: 21 May 2018 / Accepted: 29 June 2018 / Published online: 6 July 2018

(c) The Author(s) 2018

\begin{abstract}
The EXPAND Study examined the real-world efficacy and safety of rivaroxaban for the prevention of stroke and systemic embolism (SE) in Japanese patients with non-valvular atrial fibrillation (NVAF). In this sub-analysis, we compared the differences in efficacy and safety between patients with and those without history of stroke or transient ischemic attack (TIA). This multicenter, prospective, non-interventional, observational, cohort study was conducted at 684 medical centers in Japan. A total of 7141 NVAF patients aged $\geq 20$ years [mean age $71.6 \pm 9.4$ (SD) years] who were being or planned to be treated with rivaroxaban $(10 \mathrm{mg} /$ day, $43.5 \% ; 15 \mathrm{mg} /$ day, $56.5 \%)$ were followed for a mean period of $897.1 \pm 206.8$ days with a high follow-up rate $(99.7 \%)$. The primary prevention group comprised patients without history of ischemic stroke or TIA $(n=5546,77.7 \%)$, and the secondary prevention group comprised those with history of ischemic stroke or TIA ( $n=1595$, $22.3 \%)$. In the primary and secondary prevention groups, the incidence rate of stroke or SE (primary efficacy endpoint) was 0.7 and $2.2 \% / y e a r$, respectively $(P<0.001)$, and the incidence rate of major bleeding (primary safety endpoint) was 1.2 and $1.5 \% /$ year, respectively $(P=0.132)$. For major bleeding events, the incidence rate of intracranial bleeding was 0.4 and $0.8 \% /$ year $(P=0.002)$ in the primary and secondary prevention groups, respectively. This sub-analysis of the EXPAND Study showed that the Japan-specific dosages of rivaroxaban were effective and safe in Japanese NVAF patients with and those without ischemic stroke or TIA in routine clinical practice.
\end{abstract}

Keywords Non-valvular atrial fibrillation $\cdot$ Anticoagulation $\cdot$ Rivaroxaban $\cdot$ Stroke $\cdot$ Secondary prevention

\section{Abbreviations}

AF Atrial fibrillation

CABG Coronary artery bypass grafting

CI Confidence interval

$\mathrm{CrCl}$ Creatinine clearance

ISTH International Society on Thrombosis and Haemostasis

MI Myocardial infraction

NOAC Non-vitamin K antagonist oral anticoagulant

Electronic supplementary material The online version of this article (https://doi.org/10.1007/s00380-018-1219-0) contains supplementary material, which is available to authorized users.

Hiroaki Shimokawa

shimo@cardio.med.tohoku.ac.jp

Extended author information available on the last page of the article
NVAF Non-valvular atrial fibrillation

PCI Percutaneous coronary intervention

SD Standard deviation

SE Systemic embolism

TIA Transient ischemic attack

\section{Introduction}

The morbidity of stroke has been reported as $2.6 \%$ for adult population and $15.1 \%$ for elderly aged 65 years and above [1]. The elderly patients aged 75 years or above with atrial fibrillation (AF) have relatively higher risk of stroke and death [2, 3]. The risk of stroke in these patients was not different between Japan and UK [3]. As the morbidity rate continues to increase, medical expenses for treatment of 
stroke are also expected to increase [1]. The risk factors for stroke in patients with AF include those used to calculate the $\mathrm{CHA}_{2} \mathrm{DS}_{2}$-VASc score proposed in the European Society of Cardiology Guidelines in 2010 [4]. Among these risk factors, stroke/transient ischemic attack (TIA)/thromboembolism and elderly age ( $>75$ years) are associated with the highest risk [4]. History of stroke is a particularly strong risk factor for stroke, 2.5 times higher susceptibility to stroke development in affected patients [5]. In the previous study for secondary prevention of stroke, recurrent stroke continued to account for $25-30 \%$ of all stroke [6].

Rivaroxaban, one of the non-vitamin $\mathrm{K}$ antagonist oral anticoagulants (NOACs), was approved in Japan in April 2012 [7]. The efficacy and safety of rivaroxaban were demonstrated in the ROCKET AF Trial [8], and the safety of Japan-specific rivaroxaban dosages $[15 \mathrm{mg} /$ day in patients with creatinine clearance $(\mathrm{CrCl}) \geq 50 \mathrm{ml} / \mathrm{min} ; 10 \mathrm{mg} /$ day in patients with $\mathrm{CrCl} 30-49 \mathrm{ml} / \mathrm{min}$ ] was shown in the J-ROCKET AF Trial [9]. In the J-ROCKET AF Trial, evidence for the safety and efficacy in Japanese patients was not sufficiently accumulated because of the lack of data for patients with $\mathrm{CHADS}_{2}$ scores of 0 or 1 [9]. However, the recent findings of our EXPAND Study reported in 2017 and 2018 showed the efficacy and safety of rivaroxaban in routine clinical practice including patients with such scores $[10,11]$. The present report describes a sub-analysis of our EXPAND Study, addressing the primary and secondary prevention of stroke and systemic embolism (SE) with rivaroxaban in patients with non-valvular atrial fibrillation (NVAF). The primary and secondary prevention groups were defined as patients with and without history of stroke or TIA, respectively. We expect that our sub-analysis will provide the demographic characteristics by primary and secondary prevention groups and ensure the safety and efficacy of rivaroxaban of Japan-specific dosages in routine clinical practice.

\section{Methods}

\section{Research overview}

The study design and the results of the main statistical analysis of the EXPAND Study were described previously $[10,11]$. Briefly, the study was a multicenter, prospective, non-interventional, observational cohort study to demonstrate the efficacy and safety of rivaroxaban in patients with NVAF. Among patients aged $\geq 20$ years with NVAF using or planned to use rivaroxaban who provided written consent, those not meeting the exclusion criteria were enrolled [10, 11]. Patients newly treated with rivaroxaban were defined as new users, and those already using rivaroxaban before providing informed consent were defined as current users [11].
The secondary and primary prevention groups comprised patients with and those without history of ischemic stroke or TIA. The primary efficacy endpoint was the composite cumulative incidence of symptomatic stroke (ischemic or hemorrhagic) and SE, and the primary safety endpoint was the cumulative incidence of major bleeding events $[10,11]$. Major bleeding, defined using the International Society on Thrombosis and Haemostasis (ISTH) criteria, was reported by the participating physicians. The secondary safety endpoint was non-major bleeding events, including clinically relevant non-major bleeding. Events reported during the observation period were adjudicated for inclusion or exclusion by a clinical events in a committee independent of the research organization [10, 11].

\section{Statistical analysis}

We tabulated the demographics by prevention group and performed a Chi square test for each factor. The analysis set for efficacy and safety included patients with any followup information available after providing informed consent. The cumulative incidence rates of the efficacy and safety endpoints (\%/year) from the time of starting rivaroxaban to the initial onset of events, together with Kaplan-Meier estimates, were calculated by primary and secondary prevention groups to perform a log-rank test. All statistical analyses were performed using SAS software (SAS for Windows Release ver. 9.2 or later; SAS Institute Inc., Cary, NC).

\section{Governance}

The EXPAND Study was conducted in accordance with the principles of the Declaration of Helsinki, the Ethical Guidelines for Clinical Studies from the Japanese Ministry of Health, Labour and Welfare, and all applicable laws and regulations in Japan. The protocol was reviewed and approved by the Institutional Review Boards and/or Ethics Committee at all of the participating study sites. All patients provided written informed consent before enrollment. The study was registered with Clinical trials.gov (number NCT02147444) and with the University Hospital Medical Information Network clinical trials registry (number UMIN000009376).

\section{Results}

\section{Demographics of subjects enrolled by prevention group (efficacy and safety populations)}

The number of centers participating in this study was 684, and 7178 patients were registered during the enrollment period from November 20, 2012 to June 30, 2014. The target number of subjects was 7166 , where 7141 patients were 
evaluated during the observation period up to March 31, 2016. The mean follow-up period was $897.1 \pm 206.8$ days (median 918.0), and 25 patients were lost to follow-up (follow-up rate $99.7 \%$ ) [10, 11].

Table 1 shows the demographic characteristics of the patients examined in the sub-analysis. The primary and secondary prevention groups contained $5546(77.7 \%)$ and 1595 (22.3\%) patients, respectively. The following factors were noted more frequently in the secondary prevention group compared with the primary prevention group; male sex, mean age, elderly (75 years old and above), $\mathrm{CHADS}_{2}$, $\mathrm{CHA}_{2} \mathrm{DS}_{2}$-VASc and HAS-BLED scores, peripheral artery disease, diabetes mellitus, dyslipidemia, history of bleeding/ bleeding tendency, non-paroxysmal (persistent/permanent) $\mathrm{AF}$, and use of concomitant antiplatelet drugs. Meanwhile, the following factors were noted less frequently in the secondary prevention group compared with the primary prevention group; mean body weight, mean $\mathrm{CrCl}$, congestive heart failure and liver dysfunction. In secondary prevention group, the distribution of patient with history of ischemic

Table 1 Demographic and baseline clinical characteristics of patients according to primary and secondary prevention groups for stroke and systemic embolism (efficacy and safety populations)

\begin{tabular}{|c|c|c|c|c|}
\hline & Overall $(n=7141)$ & $\begin{array}{l}\text { Primary prevention } \\
\text { group }(n=5546)\end{array}$ & $\begin{array}{l}\text { Secondary prevention } \\
\text { group }(n=1595)\end{array}$ & $P$ value \\
\hline Sex, male, $n(\%)$ & $4838(67.7)$ & $3708(66.9)$ & $1130(70.8)$ & 0.003 \\
\hline Age, years, mean (SD) & $71.6(9.4)$ & $70.9(9.5)$ & $73.9(8.4)$ & $<0.001$ \\
\hline Age $\geq 75$, years, $n(\%)$ & $2919(40.9)$ & $2093(37.7)$ & $826(51.8)$ & $<0.001$ \\
\hline Body weight, kg, mean (SD) & $62.8(12.5)$ & $63.2(12.6)$ & $61.2(12.1)$ & $<0.001$ \\
\hline Creatinine clearance, $\mathrm{ml} / \mathrm{min}$, mean $(\mathrm{SD})$ & $69.7(26.2)$ & $71.2(26.8)$ & $64.7(23.2)$ & $<0.001$ \\
\hline$<30 \mathrm{ml} / \mathrm{min}, n(\%)$ & $133(2.0)$ & $104(2.0)$ & $29(1.9)$ & $<0.001$ \\
\hline $30-49 \mathrm{ml} / \mathrm{min}, n(\%)$ & $1347(19.8)$ & $968(18.3)$ & $379(24.9)$ & \\
\hline$\geq 50 \mathrm{ml} / \mathrm{min}, n(\%)$ & $5326(78.3)$ & $4213(79.7)$ & $1113(73.2)$ & \\
\hline $\mathrm{CHADS}_{2}$ score, mean (SD) & $2.1(1.3)$ & $1.6(1.0)$ & $3.7(1.0)$ & $<0.001$ \\
\hline $\mathrm{CHA}_{2} \mathrm{DS}_{2}$-VASc score, mean (SD) & $3.4(1.7)$ & $2.9(1.4)$ & $5.1(1.4)$ & $<0.001$ \\
\hline HAS-BLED score, mean (SD) & $1.4(0.9)$ & $1.2(0.7)$ & $2.3(0.8)$ & $<0.001$ \\
\hline \multicolumn{5}{|l|}{ Comorbidity } \\
\hline Congestive heart failure, $n(\%)$ & $1864(26.1)$ & $1526(27.5)$ & $338(21.2)$ & $<0.001$ \\
\hline Hypertension, $n(\%)$ & $5065(70.9)$ & $3920(70.7)$ & $1145(71.8)$ & 0.405 \\
\hline Diabetes mellitus, $n(\%)$ & $1737(24.3)$ & $1312(23.7)$ & $425(26.6)$ & 0.017 \\
\hline Angina pectoris, $n(\%)$ & $833(11.7)$ & $627(11.3)$ & $206(12.9)$ & 0.08 \\
\hline Peripheral arterial disease, $n(\%)$ & $187(2.6)$ & $130(2.3)$ & $57(3.6)$ & 0.007 \\
\hline Deep vein thrombosis, $n(\%)$ & $37(0.5)$ & $24(0.4)$ & $13(0.8)$ & 0.061 \\
\hline Pulmonary embolism, $n(\%)$ & $18(0.3)$ & $15(0.3)$ & $3(0.2)$ & 0.562 \\
\hline History of myocardial infarction, $n(\%)$ & $298(4.2)$ & $223(4.0)$ & $75(4.7)$ & 0.247 \\
\hline Aortic aneurysm, $n(\%)$ & $98(1.4)$ & $73(1.3)$ & $25(1.6)$ & 0.45 \\
\hline Dyslipidemia, $n(\%)$ & 2995 (41.9) & $2292(41.3)$ & $703(44.1)$ & 0.048 \\
\hline Liver dysfunction, $n(\%)$ & $413(5.8)$ & $339(6.1)$ & $74(4.6)$ & 0.023 \\
\hline \multicolumn{5}{|l|}{ Medical history } \\
\hline Stroke (ischemic/hemorrhagic), $n(\%)$ & $1529(21.4)$ & $86(1.6)$ & $1443(90.5)$ & $<0.001$ \\
\hline Ischemic stroke, $n(\%)$ & $1440(20.2)$ & $0(0.0)$ & $1440(90.3)$ & - \\
\hline Hemorrhagic stroke, $n(\%)$ & $135(1.9)$ & $86(1.6)$ & $49(3.1)$ & $<0.001$ \\
\hline TIA, $n(\%)$ & $219(3.1)$ & $0(0.0)$ & $219(13.7)$ & - \\
\hline SE, $n(\%)$ & $59(0.8)$ & $38(0.7)$ & $21(1.3)$ & 0.018 \\
\hline Malignant tumor, $n(\%)$ & $654(9.2)$ & $499(9.0)$ & $155(9.7)$ & 0.316 \\
\hline Bleeding and/or bleeding tendency, $n(\%)$ & $292(4.1)$ & $199(3.6)$ & $93(5.8)$ & $<0.001$ \\
\hline Dose of rivaroxaban $15 \mathrm{mg} /$ day, $n(\%)$ & $4036(56.5)$ & $3171(57.2)$ & $865(54.2)$ & 0.038 \\
\hline $\begin{array}{l}\text { Type of AF (non-paroxysmal (persistent/perma- } \\
\text { nent)), } n(\%)\end{array}$ & $3940(55.2)$ & $3022(54.5)$ & $918(57.6)$ & 0.031 \\
\hline Prior warfarin use, $n(\%)$ & $2834(39.7)$ & $2105(38.0)$ & $729(45.7)$ & - \\
\hline Use of concomitant anti-platelet drugs, $n(\%)$ & $1029(14.4)$ & $678(12.2)$ & $351(22.0)$ & $<0.001$ \\
\hline
\end{tabular}

SD standard deviation, TIA transient ischemic attack, SE systemic embolism, AF atrial fibrillation 
stroke and TIA was $90.3 \%(n=1440)$ and $13.7 \%(n=219)$, respectively.

There were 1345 (24.3\%) new users and 4201 (75.7\%) current users in the primary prevention group, and 395 $(24.8 \%)$ new users and $1200(75.2 \%)$ current users in the secondary prevention group.

\section{Efficacy}

Stroke (ischemic or hemorrhagic) and SE occurred in 92 patients $(0.7 \% /$ year) and 84 patients $(2.2 \% /$ year) in the primary and secondary prevention groups, respectively $(P<0.001)$ (Table 2, Fig. 1a). Among the secondary efficacy endpoints, the following events were significantly more common in the secondary prevention group compared with the primary prevention group; composite of stroke/ $\mathrm{SE} /$ myocardial infarction (MI)/cardiovascular death, stroke (ischemic/hemorrhagic), ischemic stroke, TIA, SE, cardiovascular death, and all-cause death (Table 2).

In the primary and secondary prevention groups, the incidence rate of stroke/SE had no difference between new and current users (primary prevention group: 0.8 vs. $0.6 \% / y e a r$;
$P=0.271$, secondary prevention group: 2.2 vs. $2.2 \% /$ year; $P=0.959)$ (Table 3$)$.

\section{Safety}

ISTH major bleeding events occurred in 159 patients (1.2\%/ year) and 56 patients (1.5\%/year) in the primary and secondary prevention groups, respectively $(P=0.132)$ (Table 2 , Fig. 1b). Among the ISTH major bleeding events, the incidence rate of intracranial hemorrhage had significant difference between the primary and secondary prevention groups ( 0.4 and $0.8 \% /$ year, $P=0.002$ ). The incidence rate of gastrointestinal bleeding did not differ significantly between the primary and secondary prevention groups ( 0.5 vs. $0.4 \%$ / year; $P=0.42$ ). The incidence rate of non-major bleeding had no difference between the 2 groups ( 4.9 and $4.9 \% / y e a r$, $P=0.963)$ (Table 2).

In the primary prevention group, the incidence rate of ISTH major bleeding and non-major bleeding had significant difference between new and current users (ISTH major bleeding: 1.7 vs. $1.0 \%$ year; $P=0.003$, non-major bleeding: 6.0 vs. $4.6 \% /$ year; $P=0.002$ ), while those rate had no

Table 2 Efficacy and safety endpoints in the primary and secondary prevention groups for stroke and systemic embolism (efficacy and safety populations)

\begin{tabular}{|c|c|c|c|c|c|c|c|}
\hline & \multicolumn{3}{|c|}{$\begin{array}{l}\text { Primary prevention group } \\
(\mathrm{n}=5546)\end{array}$} & \multicolumn{3}{|c|}{$\begin{array}{l}\text { Secondary prevention group } \\
(\mathrm{n}=1595)\end{array}$} & \multirow[t]{2}{*}{$P$ value } \\
\hline & Event, $\mathrm{n}$ & $\% /$ year & $95 \% \mathrm{CI}$ & Event, $\mathrm{n}$ & $\% /$ year & $95 \% \mathrm{CI}$ & \\
\hline \multicolumn{8}{|l|}{ Primary efficacy endpoint } \\
\hline Stroke (ischemic/hemorrhagic)/SE & 92 & 0.7 & $0.53-0.81$ & 84 & 2.2 & $1.72-2.65$ & $<0.001$ \\
\hline \multicolumn{8}{|l|}{ Secondary efficacy endpoints } \\
\hline Stroke (ischemic/hemorrhagic)/SE/MI/cardiovascular death & 173 & 1.3 & $1.08-1.45$ & 118 & 3.1 & $2.51-3.62$ & $<0.001$ \\
\hline Stroke (ischemic/hemorrhagic) & 91 & 0.7 & $0.53-0.80$ & 80 & 2.1 & $1.62-2.54$ & $<0.001$ \\
\hline Ischemic stroke & 62 & 0.5 & $0.34-0.57$ & 68 & 1.8 & $1.35-2.19$ & $<0.001$ \\
\hline Hemorrhagic stroke & 28 & 0.2 & $0.13-0.28$ & 12 & 0.3 & $0.14-0.49$ & 0.21 \\
\hline TIA & 18 & 0.1 & $0.07-0.19$ & 19 & 0.5 & $0.27-0.72$ & $<0.001$ \\
\hline SE & 2 & 0.01 & $0.00-0.03$ & 4 & 0.1 & $0.00-0.21$ & 0.008 \\
\hline Acute MI/unstable angina pectoris & 25 & 0.2 & $0.11-0.25$ & 10 & 0.3 & $0.10-0.42$ & 0.339 \\
\hline Deep vein thrombosis/pulmonary thromboembolism & 4 & 0.03 & $0.00-0.06$ & 2 & 0.05 & $0.00-0.12$ & 0.497 \\
\hline $\mathrm{PCI} / \mathrm{CABG}$ & 30 & 0.2 & $0.14-0.30$ & 14 & 0.4 & $0.17-0.55$ & 0.109 \\
\hline Cardiovascular death & 88 & 0.6 & $0.51-0.78$ & 39 & 1.0 & $0.70-1.33$ & 0.016 \\
\hline All-cause death & 190 & 1.4 & $1.19-1.58$ & 91 & 2.4 & $1.88-2.85$ & $<0.001$ \\
\hline \multicolumn{8}{|l|}{ Primary safety endpoint } \\
\hline ISTH major bleeding & 159 & 1.2 & $0.98-1.34$ & 56 & 1.5 & $1.70-1.84$ & 0.132 \\
\hline Intracranial hemorrhage & 54 & 0.4 & $0.29-0.50$ & 30 & 0.8 & $0.50-1.06$ & 0.002 \\
\hline Gastrointestinal bleeding & 67 & 0.5 & $0.37-0.61$ & 16 & 0.4 & $0.21-0.62$ & 0.42 \\
\hline Others & 38 & 0.3 & $0.19-0.37$ & 10 & 0.3 & $0.10-0.42$ & 0.942 \\
\hline \multicolumn{8}{|l|}{ Secondary safety endpoints } \\
\hline Non-major bleeding (not defined using ISTH criteria) & 668 & 4.9 & $4.51-5.25$ & 188 & 4.9 & $4.19-5.59$ & 0.963 \\
\hline
\end{tabular}

CI confidence interval, SE systemic embolism, MI myocardial infarction, TIA transient ischemic attack, PCI percutaneous coronary intervention, CABG coronary artery bypass graft, ISTH International Society on Thrombosis and Haemostasis 
Fig. 1 Kaplan-Meier analysis for the primary a efficacy and b safety endpoints according to primary and secondary prevention groups (efficacy and safety populations)
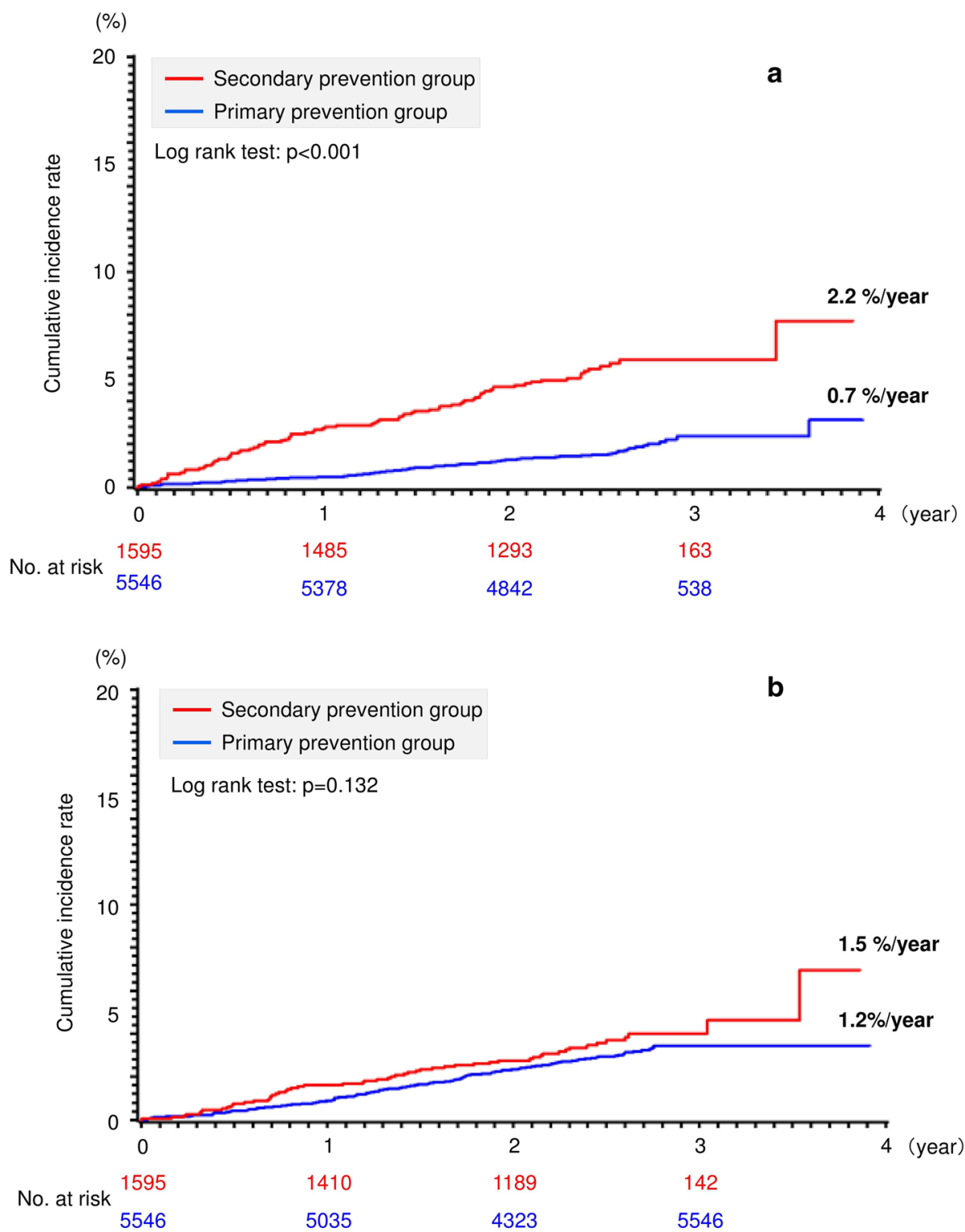

Table 3 Efficacy and safety endpoints in new and current rivaroxaban users according to primary and secondary prevention groups (efficacy and safety populations)

\begin{tabular}{|c|c|c|c|c|c|c|}
\hline \multirow[t]{3}{*}{ No. of patient } & \multicolumn{2}{|c|}{ Primary prevention group } & \multirow[t]{3}{*}{$P$ value } & \multicolumn{2}{|c|}{ Secondary prevention group } & \multirow[t]{3}{*}{$P$ value } \\
\hline & New users $(n=1345)$ & Current users $(n=4201)$ & & New users $(n=395)$ & Current users $(n=1200)$ & \\
\hline & Event, $n$ (\%/year) & Event, $n$ (\%/year) & & Event, $n$ (\%/year) & Event, $n$ (\%/year) & \\
\hline \multicolumn{7}{|l|}{ Efficacy endpoints } \\
\hline Stroke/SE & $23(0.8)$ & $69(0.6)$ & 0.271 & $19(2.2)$ & $65(2.2)$ & 0.959 \\
\hline All-cause death & $54(1.8)$ & $136(1.3)$ & 0.003 & $29(3.4)$ & $62(2.1)$ & 0.014 \\
\hline \multicolumn{7}{|l|}{ Safety endpoints } \\
\hline ISTH major bleeding & $50(1.7)$ & $109(1.0)$ & 0.003 & $15(1.8)$ & $41(1.4)$ & 0.373 \\
\hline Intracranial bleeding & $15(0.5)$ & $39(0.4)$ & 0.181 & $8(0.9)$ & $22(0.7)$ & 0.604 \\
\hline Gastrointestinal bleeding & $22(0.8)$ & $45(0.4)$ & 0.051 & $5(0.6)$ & $11(0.4)$ & 0.434 \\
\hline Others & $13(0.4)$ & $25(0.2)$ & 0.047 & $2(0.2)$ & $8(0.3)$ & 0.979 \\
\hline Non-major bleeding & $176(6.0)$ & $492(4.6)$ & 0.002 & $48(5.6)$ & $140(4.7)$ & 0.346 \\
\hline
\end{tabular}

SE systemic embolism, ISTH International Society on Thrombosis and Haemostasis 
difference between the 2 groups in the secondary prevention group (ISTH major bleeding: 1.8 vs. $1.4 \%$ year; $P=0.373$, non-major bleeding: 5.6 vs. $4.7 \% /$ year; $P=0.346$ ) (Table 3 ).

\section{Discussion}

This was a sub-analysis report by the preventive group for stroke or SE in the EXPAND Study to observe the efficacy and safety of Japan-specific dosages of rivaroxaban in Japanese patients with NVAF in a real-world clinical setting. This report provides the first evidence on the efficacy and safety of Japan-specific dosage of rivaroxaban in Japanese patients in a real-world clinical setting according to primary and secondary prevention.

Similar to the previous reports of the sub-analyses for the phase III trials of rivaroxaban (ROCKET and J-ROCKET AF Trial conducted globally and in Japan, respectively) [12, 13], the EXPAND Study showed that the incidence of stroke or SE was higher in the secondary prevention group compared with the primary prevention group. In the EXPAND Study, cardiovascular death and all-cause death were significantly higher in the secondary prevention group compared with the primary prevention group. There were no differences in the incidences of cardiovascular events, including acute MI, unstable angina pectoris, percutaneous coronary intervention/coronary artery bypass graft, or the incidence of ISTH major bleeding events. The incidence of intracranial hemorrhage was higher in the secondary prevention group compared with the primary prevention group among the sites of ISTH major bleeding events. Thus, as compared with the previous sub-analysis reports [12, 13], the EXPAND Study showed similar outcomes except for the low incidence rate of all ISTH major bleeding events.

The demographic characteristics of the patients enrolled in the EXPAND Study and the J-RHYTHM Registry were similar, demonstrating the real-world practice $[10,11,14$, 15]. The mean $\mathrm{CHADS}_{2}$ score was 1.6 and 1.4 points for the primary prevention group, and 3.7 and 3.4 points for the secondary prevention group in the EXPAND Study and J-RHYTHM Registry, respectively. Regarding the incidences of events, both the EXPAND Study and the J-RHYTHM Registry showed higher incidence of thromboembolism (ischemic stroke/TIA/SE) in the secondary prevention group [14]. Meanwhile, for ISTH major bleeding events, only the J-RHYTHM Registry showed a different incidence between primary and secondary prevention groups (primary $1.7 \%$ vs. secondary $3.0 \%, P=0.003$ ). This higher incidence of bleeding was likely to arise through the higher combined usage of warfarin and antiplatelet agents in the secondary prevention group compared with the primary prevention group in the J-RHYTHM Registry (primary $16.1 \%$ vs. secondary $32.4 \%, P<0.001$ ). The EXPAND Study also showed higher combined use of antiplatelet agents in the secondary prevention group (12.2 vs. $22.0 \%, P<0.001)$. Moreover, the HAS-BLED score in the EXPAND Study was higher in the secondary prevention group than in the primary prevention group (1.2 vs. 2.3 points, $P<0.001$ ) (Table 1$)$. However, the incidence rates of ISTH major and no-major bleeding were comparable between the primary and secondary prevention groups (ISTH major bleeding; 1.2 vs $1.5 \% /$ year, $P=0.132$ ) (non-major bleeding; 4.9 vs. $4.9 \% / y e a r, ~ P=0.963$ ) (Table 2). However, no difference was noted in the incidence of major bleeding events between the primary and secondary prevention groups (1.2 vs. $1.5 \%$ /year, $P=0.132$ ). The patients who treated with concomitant use of warfarin and aspirin had higher risk of bleeding compared with those who treated with warfarin alone [16]. Other reports have also described increased incidences of bleeding events with combined use of anticoagulant and antiplatelet drugs [17-19]. Further studies on the risk of developing bleeding events under combined use of rivaroxaban and antiplatelet drugs in comparison with combination of warfarin and antiplatelet drugs should be conducted.

In the sub-analysis for the phase III trials of rivaroxaban (ROCKET and J-ROCKET AF Trials), no significant differences were noted for efficacy (stroke/SE) or safety (ISTH major bleeding) between the primary and secondary prevention groups treated with rivaroxaban and warfarin $[12,13]$. However, in both warfarin and rivaroxaban groups, the secondary prevention group had higher incidences of stroke and SE compared with the primary prevention group, while the primary prevention group had a higher incidence of major bleeding events compared with the secondary prevention group $[12,13]$ (Table 4). In those trials, the primary prevention group had more risk factors of bleeding as components of the HAS-BLED score [20] than the secondary prevention group (Table 5). It is possible that the primary prevention group had higher risk of bleeding compared with the secondary prevention group in general.

In the EXPAND Study, the incidences of stroke and SE were similar to those in the studies mentioned above. However, regarding the incidence of major and non-major bleeding events, no significant difference was noted between the primary and secondary prevention groups in this study (Table 2). The possible reasons are that the ROCKET and J-ROCKET AF Trials did not include patients with $\mathrm{CHADS}_{2}$ scores of 0 and $1[8,9]$, while the EXPAND Study did include those with such scores $[10,11]$, and that the ROCKET and J-ROCKET AF Trial potentially had more patients with risk of bleeding in the primary prevention group than the EXPAND Study (Table 4). In addition to that, the differences in $\mathrm{CHADS}_{2}$ and HAS-BLED scores were approximately two and one scores between the 2 groups of those scores in the EXPAND Study, respectively. Consequently, the patient background of each prevention 
Table 4 Comparisons of primary and secondary prevention groups in two previous clinical trials and the EXPAND Study

(A) Demographic and baseline clinical characteristics of patients

\begin{tabular}{|c|c|c|}
\hline & \multicolumn{2}{|l|}{ Mean $\mathrm{CHADS}_{2}$ score } \\
\hline & Primary prevention group & $\begin{array}{l}\text { Secondary } \\
\text { prevention } \\
\text { group }\end{array}$ \\
\hline ROCKET AF Trial & 3 & 4 \\
\hline J-ROCKET AF Trial & 2.9 & 3.5 \\
\hline EXPAND Study & 1.6 & 3.7 \\
\hline
\end{tabular}

(B) Primary efficacy and safety endpoints

\begin{tabular}{|c|c|c|c|c|}
\hline & \multicolumn{2}{|c|}{ Primary efficacy endpoint (stroke/systemic embolism) } & \multicolumn{2}{|c|}{ Primary safety endpoints (major bleeding) } \\
\hline & Primary prevention group & $\begin{array}{l}\text { Secondary prevention } \\
\text { group }\end{array}$ & Primary prevention group & $\begin{array}{l}\text { Secondary } \\
\text { prevention } \\
\text { group }\end{array}$ \\
\hline ROCKET AF Trial (\%/year) & 1.4 & 2.8 & 4.1 & 3.1 \\
\hline J-ROCKET AF Trial (\%/year) & 0.6 & 1.7 & 4.0 & 2.4 \\
\hline EXPAND Study (\%/year) & 0.7 & 2.2 & 1.2 & 1.5 \\
\hline
\end{tabular}

Table 5 Comparisons of two previous clinical trials and the EXPAND Study according to the risk factor of bleeding as component of the HASBLED score

\begin{tabular}{|c|c|c|c|c|c|c|c|c|c|}
\hline & \multicolumn{3}{|c|}{ ROCKET AF Trial } & \multicolumn{3}{|c|}{ J-ROCKET AF Trial } & \multicolumn{3}{|c|}{ EXPAND Study } \\
\hline & $\begin{array}{l}\text { Primary } \\
\text { prevention } \\
\text { group }\end{array}$ & $\begin{array}{l}\text { Secondary } \\
\text { prevention } \\
\text { group }\end{array}$ & $P$ value & $\begin{array}{l}\text { Primary } \\
\text { prevention } \\
\text { group }\end{array}$ & $\begin{array}{l}\text { Secondary } \\
\text { prevention } \\
\text { group }\end{array}$ & $P$ value & $\begin{array}{l}\text { Primary } \\
\text { prevention } \\
\text { group }\end{array}$ & $\begin{array}{l}\text { Secondary } \\
\text { prevention } \\
\text { group }\end{array}$ & $P$ value \\
\hline Hypertension, (\%) & 96 & 85 & $<0.001$ & 95.7 & 70.3 & - & 70.7 & 71.8 & 0.405 \\
\hline Mean $\mathrm{CrCl},(\mathrm{ml} / \mathrm{min})$ & 65 & 69 & $<0.001$ & 67.1 & 68.1 & - & 71.2 & 64.7 & $<0.001$ \\
\hline $\mathrm{CrCl}<50 \mathrm{ml} / \mathrm{min},(\%)$ & - & - & - & 26.4 & 19.6 & - & 20.3 & 26.8 & $<0.001$ \\
\hline Mean age, (years) & 75 & 71 & $<0.001$ & 72.2 & 70.3 & - & 70.9 & 73.9 & $<0.001$ \\
\hline $\begin{array}{l}\text { Antiplatelet use (aspi- } \\
\text { rin), }(\%)\end{array}$ & 35 & 38 & 0.004 & 35.5 & 39.5 & - & 9.1 & 11.6 & - \\
\hline
\end{tabular}

$\mathrm{CrCl}$ creatinine clearance

group in this study did not differ significantly except for the history of stroke. As shown in Table 4, the incidence rate of stroke or SE in the secondary prevention group of the EXPAND Study was higher than that of the J-ROCKET AF Trial (2.2 and 1.7\%/year, respectively), even though mean $\mathrm{CHADS}_{2}$ score in the EXPAND Study was lower than that in the J-ROCKET AF Trial (1.6 and 2.9 points, respectively). By contrast, the incidence rate of ISTH major bleeding in both the primary and secondary prevention groups of the EXPAND Study were much lower (1.2 and 1.5\%/year, respectively) than those of the J-ROCKET AF Trial (4.0 and 2.4/year, respectively), despite mean $\mathrm{CHADS}_{2}$ scores of the secondary prevention group were comparable between the EXPAND Study and J-ROCKET AF Trial (3.7 and 3.5 points, respectively). We consider that off-label dose reduction was attributable to these results. Furthermore, it could be another reason for the higher incidence rate of stroke or SE in the secondary prevention group of the EXPAND Study that patients with acute stage of stroke within 2 weeks after the onset, who were at high risk of recurrence, were included in the EXPAND Study but not in the J-ROCKET AF Trial. We plan to clarify these issues in the ongoing exploratory analyses of our study.

In the EXPAND Study, the incidence of intracranial hemorrhage was higher in the secondary prevention group than in the primary prevention group (primary $0.4 \% / y e a r$ vs. secondary $0.8 \% /$ year, $P=0.002$ ), but gastrointestinal bleeding rate was not different between the 2 groups (primary $0.5 \%$ /year vs. secondary $0.4 \%$ year, $P=0.42$ ). These results suggest that history of stroke is a risk factor of intracranial hemorrhage, but not a risk factor of gastrointestinal bleeding. The incidence of intracranial hemorrhage was higher 
in the secondary prevention group and the warfarin-treated group compared with the primary prevention group in the J-ROCKET AF Trial [9] as well. Further studies are needed to evaluate background factors with potential impacts on bleeding events and sites in the primary and secondary prevention groups.

\section{Study limitations}

As already reported [11], the study has several limitations. In the sub-analysis as well, information bias may have had an effect on the results. Current users may not include subjects developing adverse events such as bleeding after prescription. In the sub-analysis, the incidence of major bleeding events in the primary prevention group was significantly higher in new users compared with current users. Although the difference was not significant, probably because of the difference in sample size, the incidence of major bleeding events was still higher in current users than in new users. Moreover, all-cause mortality in new users was significantly higher in both the primary and secondary prevention groups, suggesting another impact of information bias. By contrast, for the primary efficacy endpoint, the findings are considered reliable because of less selection bias.

\section{Conclusions}

The results of this sub-analysis allowed us to verify the low incidence of primary efficacy and safety endpoints in patients on Japan-specific dosages of rivaroxaban for not only primary but also secondary prevention of stroke and SE in Japanese patients with NVAF in a real-world clinical setting. In addition, as reported previously, the incidences of stroke and SE were higher in the secondary prevention group than in the primary prevention group. For bleeding events, further studies are needed to evaluate the difference in bleeding sites as our results were not consistent with those in the previous reports.

Author contributions This author Hiroaki Shimokawa takes responsibility for all aspects of the reliability and freedom from bias of the data presented and their discussed interpretation.

Funding The EXPAND Study is an investigator-initiated clinical study based on a collaborative contract with Tohoku University Hospital and Bayer Yakuhin Ltd. The company had no role in the study design, study conduct, data collection, data analysis, or manuscript preparation or submission. The details of the EXPAND Study group are provided in the Supplementary material.

\section{Compliance with ethical standards}

Conflict of interest S. U. has received personal fees from Bayer, Bristol-Myers Squibb, Boehringer Ingelheim, Daiichi Sankyo, Sanofi,
Dainippon Sumitomo, Otsuka, Takeda, Astellas, AstraZeneca, Sanwa Kagaku, Shionogi, Mitsubishi Tanabe, and Pfizer, outside the submitted work. A. T. and K. K. has nothing to disclose. H. I. has received personal fees from Bayer, Boehringer Ingelheim, Daiichi-Sankyo, and Bristol-Myers Squibb, outside the submitted work. T. K. has received grants and personal fees from Daiichi Sankyo, Bayer, Pfizer, Chugai, Boehringer Ingelheim, Mitsubishi Tanabe, Shionogi, Astellas, and MSD; personal fees from Bristol-Myers Squibb, Sanofi, and AstraZeneca; and grants from Takeda, Kissei, Kyowa Hakko Kirin, EA Pharma, Asahi Kasei, Otsuka, Torii, Eisai, Ono, Zeria, and Dainippon Sumitomo, outside the submitted work. T. Y. has received grants and personal fees from Bayer, Daiichi Sankyo, Bristol-Myers Squibb, and Mitsubishi Tanabe; and personal fees from Pfizer, Eisai, Ono, Toa Eiyo, and Nippon Boehringer Ingelheim, outside the submitted work. W. S. has received grants and personal fees from Bayer, Daiichi Sankyo, Nippon Boehringer Ingelheim, Bristol-Myers Squibb, Pfizer, Eisai, Ono, and Mitsubishi Tanabe, outside the submitted work. T. I. reports grants and personal fees from Daiichi-Sankyo, personal fees from Bayer, grants and personal fees from Bristol-Myers Squibb, personal fees from Pfizer, grants from Boehringer Ingelheim, outside the submitted work. M. $\mathrm{K}$. has received personal fees from Tohoku University, during the conduct of the study; and personal fees from Bayer, outside the submitted work. K. F. has received personal fees from Bayer, outside the submitted work. H. O. has received advisory fees from Daiichi-Sankyo and Bayer, outside the submitted work. H. S. has received lecture fees from Bayer, and Daiichi Sankyo, outside the submitted work.

Open Access This article is distributed under the terms of the Creative Commons Attribution 4.0 International License (http://creativeco mmons.org/licenses/by/4.0/), which permits unrestricted use, distribution, and reproduction in any medium, provided you give appropriate credit to the original author(s) and the source, provide a link to the Creative Commons license, and indicate if changes were made.

\section{References}

1. Levine GN, Bates ER, Bittl JA, Brindis RG, Fihn SD, Fleisher LA, Granger CB, Lange RA, Mack MJ, Mauri L, Mehran R, Mukherjee D, Newby LK, O'Gara PT, Sabatine MS, Smith PK, Smith SC Jr (2016) 2016 ACC/AHA guideline focused update on duration of dual antiplatelet therapy in patients with coronary artery disease: a report of the American College of Cardiology/American Heart Association Task Force on clinical practice guidelines: an update of the 2011 ACCF/AHA/SCAI guideline for percutaneous coronary intervention, 2011 ACCF/AHA guideline for coronary artery bypass graft surgery, 2012 ACC/AHA/ACP/AATS/PCNA/ SCAI/STS guideline for the diagnosis and management of patients with stable ischemic heart disease, $2013 \mathrm{ACCF} / \mathrm{AHA}$ guideline for the management of ST-elevation myocardial infarction, 2014 AHA/ACC guideline for the management of patients with nonST-elevation acute coronary syndromes, and 2014 ACC/AHA guideline on perioperative cardiovascular evaluation and management of patients undergoing noncardiac surgery. Circulation 134:e123-e155

2. Lip GYH, Clementy N, Pericart L, Banerjee A, Fauchier L (2015) Stroke and major bleeding risk in elderly patients aged $\geq 75$ years with atrial fibrillation. Stroke 46:143-150

3. Senoo K, An Y, Ogawa H, Lane DA, Wolff A, Shantsila E, Akao M, Lip GY (2016) Stroke and death in elderly patients with atrial fibrillation in Japan compared with the United Kingdom. Heart 102:1878-1882

4. Kirchhof P, Benussi S, Kotecha D, Ahlsson A, Atar D, Casadei B, Castellá M, Diener HC, Heidbuchel H, Hendriks J, Hindricks G, 
Manolis AS, Oldgren J, Alexandru Popescu B, Schotten U, Van Putte B, Vardas P (2016) 2016 ESC guidelines for the management of atrial fibrillation developed in collaboration with EACTS. Eur Heart J 37:2893-2962

5. Stroke Risk in Atrial Fibrillation Working Group (2007) Independent predictors of stroke in patients with atrial fibrillation: a systematic review. Neurology 69:546-554

6. Hankey GJ (2014) Secondary stroke prevention. Lancet Neurol 13:178-194

7. Rivaroxaban approval in Japan. https://www.xarelto.jp/ja/home/ index.php. Accessed 25 Jun 2018

8. Patel MR, Mahaffey KW, Garg J, Pan G, Singer DE, Hacke W, Breithardt G, Halperin JL, Hankey GJ, Piccini JP, Becker RC, Nessel CC, Paolini JF, Berkowitz SD, Fox KA, Califf RM, Investigators ROCKETAF (2011) Rivaroxaban versus warfarin in nonvalvular atrial fibrillation. N Eng J Med 365:883-891

9. Hori M, Matsumoto M, Tanahashi N, Momomura S, Uchiyama S, Goto S, Izumi T, Koretsune Y, Kajikawa M, Kato M, Ueda H, Iwamoto K, Tajiri M, J-ROCKET AF study investigators (2012) Rivaroxaban vs. warfarin in Japanese patients with atrial fibrillation-the J-ROCKET AF study. Circ J 76:2104-2111

10. Ikeda T, Atarashi H, Inoue H, Uchiyama S, Kitazono T, Yamashita T, Shimizu W, Kamouchi M, Kaikita K, Fukuda K, Origasa H, Sakuma I, Saku K, Okumura Y, Nakamura Y, Morimoto H, Matsumoto N, Tsuchida A, Ako J, Sugishita N, Shimizu S, Shimokawa H (2016) Study design and baseline characteristics of the EXPAND study: evaluation of effectiveness and safety of Xa inhibitor, rivaroxaban for the prevention of stroke and systemic embolism in a nationwide cohort of Japanese patients diagnosed as non-valvular atrial fibrillation. Tohoku J Exp Med 240:259-268

11. Shimokawa H, Yamashita T, Uchiyama S, Kitazono T, Shimizu W, Ikeda T, Kamouchi M, Kaikita K, Fukuda K, Origasa H, Sakuma I, Saku K, Okumura Y, Nakamura Y, Morimoto H, Matsumoto N, Tsuchida A, Ako J, Sugishita N, Shimizu S, Atarashi H, Inoue H (2018) The EXPAND Study: efficacy and safety of rivaroxaban in Japanese patients with non-valvular atrial fibrillation. Int J Cardiol 258:126-132

12. Hankey GJ, Patel MR, Stevens SR, Becker RC, Breithardt G, Carolei A, Diener HC, Donnan GA, Halperin JL, Mahaffey KW, Mas JL, Massaro A, Norrving B, Nessel CC, Paolini JF, Roine RO, Singer DE, Wong L, Califf RM, Fox KA, Hacke W, ROCKET AF Steering Committee Investigators (2012) Rivaroxaban compared with warfarin in patients with atrial fibrillation and previous stroke or transient ischaemic attack: a subgroup analysis of ROCKET AF. Lancet Neurol 11:315-322
13. Tanahashi N, Hori M, Matsumoto M, Momomura S, Uchiyama S, Goto S, Izumi T, Koretsune Y, Kajikawa M, Kato M, Ueda H, Iwamoto K, Tajiri M, J-ROCKET AF Study Investigators (2013) Rivaroxaban versus warfarin in Japanese patients with nonvalvular atrial fibrillation for the secondary prevention of stroke: a subgroup analysis of J-ROCKET AF. J Stroke Cerebrovasc Dis 22:1317-1325

14. Kodani E, Atarashi H, Inoue H, Okumura K, Yamashita T, Origasa H, Registry Investigators J-RHYTHM (2016) Secondary prevention of stroke with warfarin in patients with nonvalvular atrial fibrillation: subanalysis of the J-RHYTHM Registry. J Stroke Cerebrovasc Dis 25:585-599

15. Atarashi H, Inoue H, Okumura K, Yamashita T, Kumagai N, Origasa H, Registry Investigators J-RHYTHM (2011) Present status of anticoagulation treatment in Japanese patients with atrial fibrillation: a report from the J-RHYTHM Registry. Circ J 75:1328-1333

16. Lip GY, Frison L, Halperin JL, Lane DA (2011) Comparative validation of a novel risk score for predicting bleeding risk in anticoagulated patients with atrial fibrillation: the HAS-BLED (hypertension, abnormal renal/liver function, stroke, bleeding history or predisposition, labile INR, elderly, drugs/alcohol concomitantly) Score. J Am Coll Cardiol 57:173-180

17. Bekelis K, Chang CH, Malenka D, Morden NE (2018) Direct oral anticoagulant and antiplatelet combination therapy: hemorrhagic events in coronary artery stent recipients. J Clin Neurosci 50:24-29

18. Chiarito M, Cao D, Cannata F, Godino C, Lodigiani C, Ferrante G, Lopes RD, Alexander JH, Reimers B, Condorelli G, Stefanini GG (2018) Direct oral anticoagulants in addition to antiplatelet therapy for secondary prevention after acute coronary syndromes: a systematic review and meta-analysis. JAMA Cardiol 3:234-241

19. Toyoda K, Yasaka M, Iwade K, Nagata K, Koretsune Y, Sakamoto T, Uchiyama S, Gotoh J, Nagao T, Yamamoto M, Takahashi JC, Minematsu K, Bleeding with Antithrombotic Therapy (BAT) Study Group (2008) Dual antithrombotic therapy increases severe bleeding events in patients with stroke and cardiovascular disease: a prospective, multicenter, observational study. Stroke 39:1740-1745

20. Roldan V, Marin F, Manzano FS, Gallego P, Vílchez JA, Valdés M, Vicente V, Lip GY (2013) The HAS-BLED score has better prediction accuracy for major bleeding than $\mathrm{CHADS}_{2}$ or $\mathrm{CHA}_{2} \mathrm{DS}_{2}$-VASc scores in anticoagulated patients with atrial fibrillation. J Am Coll Cardiol 62:2199-2204

\section{Affiliations}

\section{Shinichiro Uchiyama ${ }^{1} \cdot$ Hirotsugu Atarashi ${ }^{2} \cdot$ Hiroshi Inoue ${ }^{3} \cdot$ Takanari Kitazono $^{4} \cdot$ Takeshi Yamashita $^{5}$. Wataru Shimizu $^{6} \cdot$ Takanori Ikeda $^{7} \cdot$ Masahiro Kamouchi $^{8} \cdot$ Koichi Kaikita $^{9} \cdot$ Koji Fukuda $^{10} \cdot$ Hideki Origasa $^{11}$. Hiroaki Shimokawa ${ }^{12}$ (i)}

1 Center for Brain and Cerebral Vessels, Sanno Hospital and Sanno Medical Center, International University of Health and Welfare, 8-5-35 Akasaka, Minato-ku, Tokyo 107-0052, Japan

2 Minamihachioji Hospital, 3-18-12 Koyasu-cho, Hachioji, Tokyo 192-0904, Japan

3 Saiseikai Toyama Hospital, 33-1 Kusunoki, Toyama, Toyama 931-8533, Japan
4 Department of Medicine and Clinical Science, Graduate School of Medical Sciences, Kyushu University, 3-1-1 Maidashi, Higashi-ku, Fukuoka, Fukuoka 812-8582, Japan

5 Cardiovascular Institute Hospital, 3-2-19 Nishiazabu, Minato-Ku, Tokyo 106-0031, Japan

6 Department of Cardiovascular Medicine, Graduate School of Medicine, Nippon Medical School, 1-1-5 Sendagi, Bunkyo-ku, Tokyo 113-8602, Japan 
7 Department of Cardiovascular Medicine, Toho University Faculty of Medicine, 5-21-16 Omorinishi, Ota-ku, Tokyo 143-8540, Japan

8 Department of Health Care Administration and Management, Center for Cohort Study, Kyushu University Graduate School of Medical Sciences, 3-1-1 Maidashi, Higashi-ku, Fukuoka, Fukuoka 812-8582, Japan

9 Department of Cardiovascular Medicine, Graduate School of Medical Sciences, Kumamoto University, 2-39-1

Kurokami Chuo-ku, Kumamoto, Kumamoto 860-8555, Japan
10 Division of Heart Rhythm, International University of Health and Welfare Hospital, International University of Health and Welfare, 537-3 Iguchi, Nasushiobara, Tochigi 537-3, Japan

11 Division of Biostatistics and Clinical Epidemiology, University of Toyama Graduate School of Medicine, 2630 Sugitani, Toyama, Toyama 930-0194, Japan

12 Department of Cardiovascular Medicine, Tohoku University Graduate School of Medicine, 1-1 Seiryomachi, Aoba-ku, Sendai, Miyagi 980-8574, Japan 